Aldinger, K. R., T. M. Terhune II, P. B. Wood, D. A. Buehler, M. H. Bakermans, J. L. Confer, D. J. Flaspohler, J. L. Larkin, J. P. Loegering, K. L. Percy, A. M. Roth, and C. G. Smalling. 2015. Variables associated with nest survival of Golden-winged Warblers (Vermivora chrysoptera) among vegetation communities commonly used for nesting. Avian Conservation and Ecology 10(1): 6. http://dx.doi.org/10.5751/ACE-00748-100106 Copyright (C) 2015 by the author(s). Published here under license by the Resilience Alliance.

Research Paper

\title{
Variables associated with nest survival of Golden-winged Warblers (Vermivora chrysoptera) among vegetation communities commonly used for nesting
}

\author{
Kyle R. Aldinger ${ }^{1}$, Theron M. Terhune $I^{2}{ }^{2}$, Petra B. Wood $^{3}$, David A. Buehler ${ }^{4}$, Marja H. Bakermans ${ }^{5}$, John L. Confer $^{6}$, David J. \\ Flaspohler $^{7}$, Jeffrey L. Larkin ${ }^{8}$, John P. Loegering ${ }^{9}$, Katie L. Percy ${ }^{4}$, Amber M. Roth $^{7}$ and Curtis G. Smalling ${ }^{10}$ \\ ${ }^{1}$ West Virginia Cooperative Fish and Wildlife Research Unit, West Virginia University, ${ }^{2}$ Tall Timbers Research Station and Land \\ Conservancy, ${ }^{3}$ U.S. Geological Survey, West Virginia Cooperative Fish and Wildlife Research Unit, West Virginia University, \\ ${ }^{4}$ Department of Forestry, Wildlife, and Fisheries, University of Tennessee, ${ }^{5}$ Department of Biology and Biotechnology, Worcester \\ Polytechnic Institute, ${ }^{6}$ Department of Biology, Ithaca College, ${ }^{7}$ School of Forest Resources and Environmental Science, Michigan \\ Technological University, ${ }^{8}$ Department of Biology, Indiana University of Pennsylvania, ${ }^{9}$ Natural Resources Department, University \\ of Minnesota, Crookston, ${ }^{10}$ Audubon North Carolina, Mountain Office
}

\begin{abstract}
Among shrubland- and young forest-nesting bird species in North America, Golden-winged Warblers (Vermivora chrysoptera) are one of the most rapidly declining partly because of limited nesting habitat. Creation and management of high quality vegetation communities used for nesting are needed to reduce declines. Thus, we examined whether common characteristics could be managed across much of the Golden-winged Warbler's breeding range to increase daily survival rate (DSR) of nests. We monitored 388 nests on 62 sites throughout Minnesota, Wisconsin, New York, North Carolina, Pennsylvania, Tennessee, and West Virginia. We evaluated competing DSR models in spatial-temporal (dominant vegetation type, population segment, state, and year), intraseasonal (nest stage and time-within-season), and vegetation model suites. The best-supported DSR models among the three model suites suggested potential associations between daily survival rate of nests and state, time-within-season, percent grass and Rubus cover within $1 \mathrm{~m}$ of the nest, and distance to later successional forest edge. Overall, grass cover (negative association with DSR above 50\%) and Rubus cover (DSR lowest at about 30\%) within $1 \mathrm{~m}$ of the nest and distance to later successional forest edge (negative association with DSR) may represent common management targets across our states for increasing Golden-winged Warbler DSR, particularly in the Appalachian Mountains population segment. Context-specific adjustments to management strategies, such as in wetlands or areas of overlap with Blue-winged Warblers (Vermivora cyanoptera), may be necessary to increase DSR for Golden-winged Warblers.
\end{abstract}

\section{Variables associées à la survie des nids de Paruline à ailes dorées (Vermivora chrysoptera) parmi les communautés végétales fréquemment utilisées pour nicher}

RÉSUMÉ. Parmi les espèces d'oiseaux d'Amérique du Nord qui nichent dans les milieux arbustifs et les jeunes forêts, la Paruline à ailes dorées (Vermivora chrysoptera) est l'une de celles dont les populations diminuent le plus rapidement en raison du peu de milieux de nidification. Afin de freiner cette baisse, la création et l'aménagement de communautés végétales de qualité sont nécessaires pour la nidification de l'espèce. Nous avons examiné s'il était possible d'aménager sur la base de caractéristiques communes dans une grande partie de l'aire de reproduction de cette paruline pour augmenter le taux de survie quotidien des nids (TSQ). Nous avons suivi 388 nids dans 62 stations réparties au Minnesota, au Wisconsin, dans l'État de New York, en Caroline du Nord, en Pennsylvanie, au Tennessee et en Virginie occidentale. Nous avons évalué trois séries de modèles de TSQ fondés sur les caractéristiques spatio-temporelles (type de végétation dominante, segment de la population, État et année), intrasaisonnières (stade du nid et moment durant la saison) et végétales. Parmi tous les modèles, les meilleurs montraient une association potentielle du taux de survie quotidien des nids avec l'État, le moment durant la saison, le pourcentage d'herbacées, le couvert de Rubus dans un rayon d'un mètre autour du nid et la distance à une lisière de forêt plus âgée. Dans l'ensemble, le couvert d'herbacées (association négative avec le TSQ lorsque supérieur à $50 \%$ ) et le couvert de Rubus (TSQ le plus faible à $30 \%$ environ) dans un rayon d'un mètre autour du nid et la distance à une lisière de forêt plus âgée (association négative avec le TSQ) pourraient représenter des cibles d'aménagement communes visant à améliorer le TSQ de la Paruline à ailes dorées dans les États examinés, en particulier pour le segment de population qui occupe les Appalaches. Les stratégies d'aménagement pourraient devoir prévoir des ajustements spécifiques au contexte, tels que dans des milieux humides ou des endroits qu'occupe également la Paruline à ailes bleues (Vermivora cyanoptera).

Key Words: conservation; daily survival rate; management; vegetation 


\section{INTRODUCTION}

Loss of shrublands and young forests in eastern North America has contributed to widespread population declines of bird species that nest in these vegetation types (Hunter et al. 2001, Sauer et al. 2014). Recently, state and federal agencies initiated efforts (e.g., the Working Lands for Wildlife agreement between the U.S. Natural Resource Conservation Service and U.S. Fish and Wildlife Service) to create and restore shrublands and young forests to benefit bird populations (Ciuzio et al. 2013). To increase their effectiveness, conservation efforts require information about the link between spatial, temporal, and vegetation characteristics and parameters such as daily survival rate (DSR) of nests across broad spatial scales and different vegetation communities.

Golden-winged Warblers (Vermivora chrysoptera) are one of the most rapidly declining bird species in North America (Sauer et al. 2014), resulting in a petition and status review for Endangered Species Act listing in the United States, which is ongoing. Their status has resulted in increased attention from conservation agencies and highlighted the importance of creating and managing vegetation communities used for breeding (Ciuzio et al. 2013). Several site-specific studies related Golden-winged Warbler nest survival to habitat characteristics at various scales, including nest sites (Bulluck and Buehler 2008, Aldinger and Wood 2014, Streby et al. 2014), territories (Confer et al. 2003), clusters of territories (Kubel and Yahner 2008, Confer et al. 2010, Roth et al. 2014), and study sites (Bulluck et al. 2013), and were seldom in agreement about which characteristics were linked to nest survival. A cohesive assessment of DSR that includes multiple states across the breeding range and the various vegetation communities used for nesting may unify disparate findings.

In our study, we investigated whether a common set of vegetation characteristics was linked to DSR across various geographic locations and vegetation communities used by nesting Goldenwinged Warblers. If such relationships exist and these characteristics can be identified, then regional conservation strategies can be developed to manipulate the characteristics likely to increase DSR. Although these relationships may be bestidentified with controlled, manipulative experiments, descriptive studies like ours are valuable in documenting variation in DSR and developing preliminary management guidelines. Such a large-scale investigation is warranted because studies have documented environmental conditions wherein reproductive performance was too low to support stable populations without immigration (Confer et al. 2003, 2010, Kubel and Yahner 2008). Until the outcome of manipulating vegetation to improve reproductive performance is better understood, conservation strategies designed to do so may be ineffective or counterproductive.

Predation is the presumed cause of nearly all Golden-winged Warbler nest failures, particularly by small mammals and snakes (Kubel and Yahner 2008, Confer et al. 2010, Bulluck et al. 2013, Streby et al. 2014), similar to other ground-nesting birds (Söderström et al. 1998, Thompson and Burhans 2003, Weatherhead and Blouin-Demers 2004, Sperry et al. 2008). Nest predation patterns can be best explained with a hierarchical, multiscale modeling approach, where landscape-scale characteristics are most important and provide context for predation patterns at the nest-site scale (Thompson et al. 2002). Golden-winged Warbler populations may face a diverse array of nest predators locally, e.g., wetlands versus uplands (Confer et al. 2010), and regionally, e.g., southern (Bulluck et al. 2013) versus northern latitudes (Streby et al. 2014), because of their vast breeding distribution and variety of vegetation communities used for nesting (Confer et al. 2011). Consequently, we used a hierarchical, multiscale approach to model nest survival, which included characteristics from the scale of the population segment (landscape-scale) to the nest site, e.g., vegetation cover around the nest.

Our objective was to determine if a common set of vegetation characteristics was associated with DSR of nests across the Golden-winged Warbler's breeding range. We examined multiple hypotheses related to DSR, each of which was embedded in one of three model suites including spatial-temporal, intraseasonal, or vegetation covariates. Although we did not comprehensively sample the entire breeding range or weight our sample by population density, we sampled nests from 62 sites throughout 7 states during 5 years and included all known vegetation communities commonly used by Golden-winged Warblers for nesting (Confer et al. 2011).

\section{METHODS}

\section{Study area}

During 2008-2012, we located and monitored nests in known Golden-winged Warbler populations across seven states (Fig. 1, Table 1). Because sites within each state generally were closer in proximity to each other than sites in other states and had similar vegetation communities and management regimes, we chose to consider all sites within a state as providing replicate data. Within each state, we located and monitored nests (range $=8-101$ nests per state, $\mathrm{n}=388$ nests total) at multiple sites (range $=2-20$ sites per state, $n=62$ sites total), defined as discrete areas dominated by similar vegetation communities and management histories relevant to Golden-winged Warbler nesting. To find the largest sample of nests possible, we selected sites that represented the predominant vegetation communities used for nesting in each state and across the breeding range (summarized in Confer et al. 2011). All sites had a mosaic of vegetation types dominated by grasses, forbs, low shrubs, saplings, and scattered canopy trees surrounded by near 100\% closed-canopy forest in both upland and wetland settings. All sites had recent ( $<25$ years), ongoing, or both recent and ongoing management-related disturbances that created nesting vegetation in predominantly forested landscapes. Two states (Minnesota and Wisconsin) were within the Great Lakes population segment and five (New York, Pennsylvania, West Virginia, North Carolina, and Tennessee) were within the possibly disjunct Appalachian Mountains population segment (Fig. 1; Roth et al. 2012). We monitored nests during 2008-2010 in Minnesota, Wisconsin, and New York; during 2008-2012 in Pennsylvania, West Virginia, and Tennessee; and during 2010 in North Carolina. Among population segments, $85 \%(\mathrm{n}=330)$ of nests were in the Appalachian Mountains and $15 \%(n=58)$ were in the Great Lakes. 
Table 1. We monitored Golden-winged Warbler (Vermivora chrysoptera) nests $(\mathrm{n}=388)$ at multiple sites $(\mathrm{n}=62)$ across seven states, representing the vegetation communities commonly used for nesting (Confer et al. 2011).

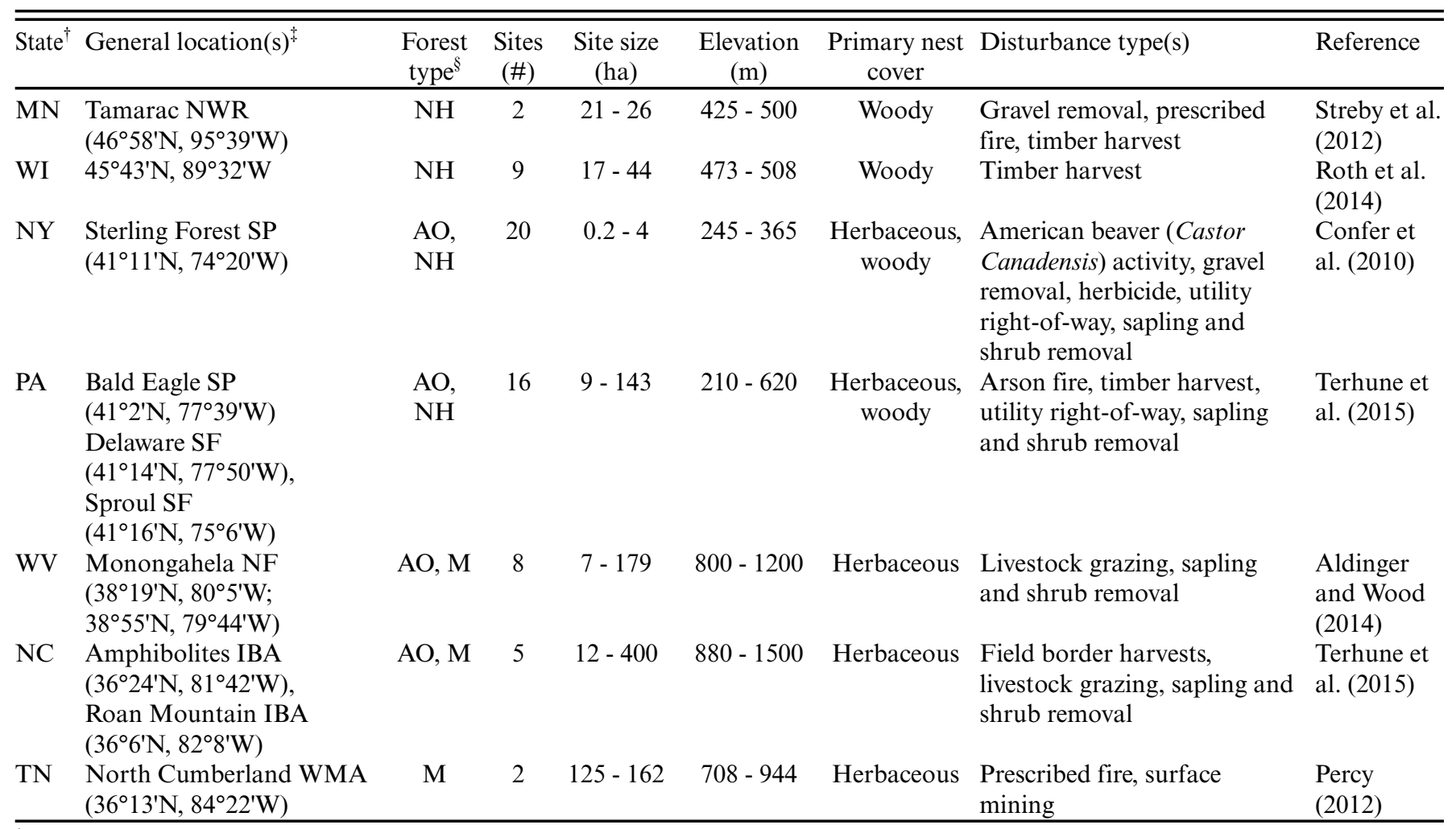

\footnotetext{
${ }^{\dagger}$ Minnesota (MN), Wisconsin (WI), New York (NY), Pennsylvania (PA), West Virginia (WV), North Carolina (NC), Tennessee (TN)

* Important Bird Area (IBA), National Forest (NF), National Wildlife Refuge (NWR), State Forest (SF), State Park (SP), Wildlife Management Area (WMA).

${ }^{\S}$ Dyer (2006): Appalachian oak (AO), mesophytic (M), northern hardwood (NH).
}

Fig. 1. Sample sizes of nests by state (Minnesota [MN], Wisconsin [WI], New York [NY], Pennsylvania [PA], West Virginia [WV], North Carolina [NC], and Tennessee [TN]) and year (2008-2012) and approximate locations of groups of sites (n $=2-20$ sites per group of sites, $\mathrm{n}=62$ sites total) across the Golden-winged Warbler's (Vermivora chrysoptera) breeding range (Roth et al. 2012).

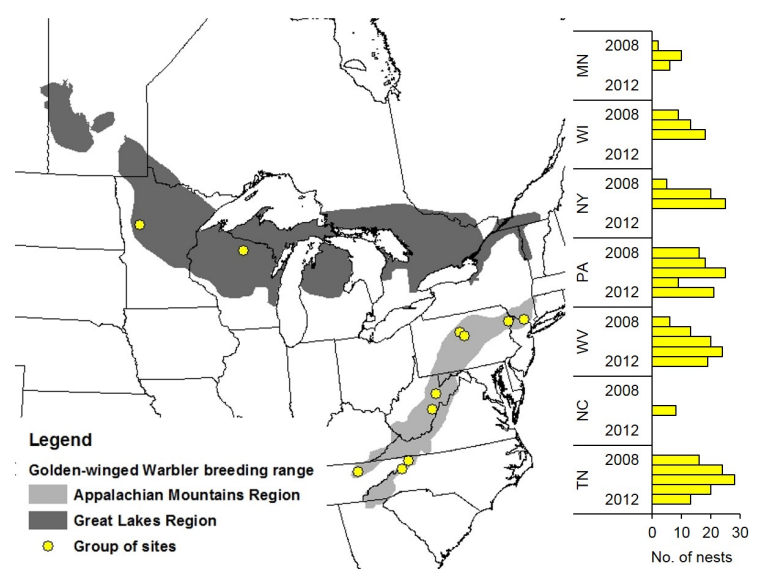

\section{Nest monitoring}

We monitored Golden-winged Warbler nests using methods outlined in Martin and Geupel (1993), including searching for nests as soon as males established territories, following parental cues to locate nests during building, egg-laying, incubation, and brooding, minimizing presence of visible markers and dead-end trails around nests, and using sticks to part vegetation when checking nests. We minimized the potential bias of discovering a disproportionate number of nests in open vegetation types by following female behavioral cues, such as tzip calls (Ficken and Ficken 1968), nest material or food carries, and inconspicuous movements to areas with nesting cover, to locate nests (rather than systematic searching). We tried not to disturb females during nest construction or egg-laying because females readily abandon nests during these stages (Confer et al. 2010). We checked nests every 2-4 days initially and more frequently as fledging approached to maximize accuracy of nest fate determination while minimizing potential negative impacts of visiting nests. We defined the fledged brood size as the number of nestlings observed on the last day we monitored the nest prior to fledging. If at least one Golden-winged Warbler nestling fledged, we considered a nest successful. Because of potential bias with determining nest fate solely from nest condition or presence of fledglings, we used a combination of nest condition, presence and age of fledglings, and presence and behavior of color-marked 
adults to determine nest fate. We checked all nests within 4 days of the date of their fate, minimizing the potential distances traveled and neighboring territories encountered by fledglings (Streby and Andersen 2013). Golden-winged Warblers raise one brood per season and generally renest up to two times after nest failure (Tennessee and Ontario, Bulluck et al. 2013; Minnesota, Streby et al. 2014; West Virginia, Aldinger and Wood 2014; New York, J. L. Confer, personal communication), although more than two renests are possible (K. Aldinger, unpublished data).

\section{Vegetation sampling}

We collaboratively developed a standardized vegetation sampling protocol through meetings of the Golden-winged Warbler Working Group (Buehler et al. 2007) and states communicated annually to ensure data consistency. We selected variables thought to be important correlates of Golden-winged Warbler nest-site selection and DSR (e.g., Confer et al. 2003, Bulluck and Buehler 2008). Study personnel directly involved in the development of the vegetation sampling protocol trained their observers prior to vegetation data collection. Because of logistic constraints during peak nest searching and monitoring times, we started sampling vegetation at nests approximately one month after the nesting season began and completed vegetation sampling within one month (across states: mean $=3$ July, median $=30$ June, range $=$ 6 June-22 August). At the time of sampling, vegetation had reached full leaf development so vegetation growth stage was approximately consistent among nests. We sampled vegetation once a nesting attempt finished.

We measured the nest rim height above the soil surface. Using a measuring tape or global positioning system unit in the field or the most recent 1-m resolution National Agriculture Imagery Program aerial photographs in a geographic information system, we measured the distance from the nest to the nearest later successional forest edge, which generally forms a conspicuous part of a male's territory (Confer et al. 2011). For vegetation sampling, a "later successional forest" had a near $100 \%$ closed-canopy formed by trees $>10 \mathrm{~cm}$ in $\mathrm{dbh}$ and an "edge" was the interface between later successional forest and vegetated areas lacking a near $100 \%$ closed-canopy formed by trees $>10 \mathrm{~cm}$ in $\mathrm{dbh}$. The canopy closure within later successional forests generally prevented growth of patchy shrubs and dense herbaceous cover needed for nesting. Within a $1-\mathrm{m}$ radius of the nest, we estimated percent ground cover of grasses (grasses [Poaceae], sedges [Cyperaceae], and rushes [Juncaceae]), forbs (nongrass herbaceous vegetation), woody vegetation, and Rubus. Observers positioned perpendicularly intersecting ruled ropes over the nest, stood outside the 1-m markers of the ropes, and visually estimated the percent cover of each vegetation type, the sum of which could not exceed $100 \%$. Some studies suggest that visual estimation produces unreliable results from observer bias (Luscier et al. 2006), however we believe visual estimation yielded a valid index of vegetative cover because we collaboratively developed standardized protocols, trained all observers, and worked in groups of two or more to collect vegetation data (Kercher et al. 2003, Helm and Mead 2004, Symstad et al. 2008). Furthermore, plots smaller than 1-m radius were successfully used to describe Golden-winged Warbler habitat (Confer et al. 2003). To estimate vegetation density (Nudds 1977) for each cardinal direction, the first observer stood at the nest and counted the number of $20-\mathrm{cm}$ squares on a board ( $2 \mathrm{~m}$ tall, $40 \mathrm{~cm}$ wide) that were $>50 \%$ obscured by vegetation when a second observer held the board $10 \mathrm{~m}$ from the nest, perpendicular to the line-of-sight of the first observer. For each cardinal direction, we divided the number of obscured squares by the total number of squares on the board $(n=20)$. We averaged these four vegetation density percentages to obtain a single estimate of vegetation density at each nest.

\section{Modeling of daily survival rate}

We developed a priori candidate models (Table 2) of Goldenwinged Warbler nest DSR considering three primary sources of model variation:

Table 2. Definitions and notation of all candidate models used in model suites for evaluating the association of spatial-temporal (Model Suite I), intraseasonal (Model Suite II), and vegetation (Model Suite III) covariates with daily survival rate of Goldenwinged Warbler (Vermivora chrysoptera) nests using program MARK (ver. 7.1, Colorado State University, Ft. Collins, Colorado, USA).

\begin{tabular}{|c|c|}
\hline Covariate of interest & Model notation \\
\hline \multicolumn{2}{|c|}{ Model Suite I: Spatial-temporal covariates ( $\mathrm{n}=7$ models) } \\
\hline Intercept only & Constant \\
\hline Year & Year \\
\hline State & State \\
\hline Year and state & Year + State \\
\hline Year and state interaction & Year $\times$ State \\
\hline Population segment & PopSeg \\
\hline Dominant vegetation type & VegType \\
\hline \multicolumn{2}{|c|}{ Model Suite II: Intraseasonal covariates $(n=4 \text { models })^{\dagger}$} \\
\hline Linear time trend & $\mathrm{T}$ \\
\hline Quadratic time trend & TT \\
\hline Nest stage & Stage \\
\hline \multicolumn{2}{|c|}{ Model Suite III: Vegetation covariates $(\mathrm{n}=38 \text { models })^{\dagger}$} \\
\hline Forb cover ${ }^{\ddagger}$ & $\mathrm{FC}$ \\
\hline Woody cover ${ }^{\ddagger}$ & WC \\
\hline Rubus cover & $\mathrm{RC}$ \\
\hline Grass cover ${ }^{\ddagger}$ & GC \\
\hline Combined (forb + grass) herbaceous cover ${ }^{\ddagger}$ & Herb \\
\hline Combined (Rubus + woody) shrub cover ${ }^{\ddagger}$ & Shrub \\
\hline Forb, grass, Rubus, and woody cover & $\begin{array}{l}\mathrm{FC}+\mathrm{GC}+\mathrm{RC} \\
+\mathrm{WC}\end{array}$ \\
\hline Vegetation density percentage within $10 \mathrm{~m}$ & VegDen \\
\hline Distance to later successional forest edge & Edge \\
\hline Nest height & NestHt \\
\hline $\begin{array}{l}\left.\text { Quadratic (e.g., } \mathrm{GC}^{2} \text { ) or cubic (e.g., } \mathrm{GC}^{3}\right) \\
\text { vegetation covariate }^{\S}\end{array}$ & $\begin{array}{l}\mathrm{GC}+\mathrm{GC}^{2} \text { or } \\
\mathrm{GC}+\mathrm{GC}^{2}+ \\
\mathrm{GC}^{3}\end{array}$ \\
\hline $\begin{array}{l}\text { Linear vegetation covariate (e.g., GC) } \\
\text { interaction with covariate(s) in best- } \\
\text { supported model from Model Suite I (e.g., } \\
\text { State) }\end{array}$ & $\mathrm{GC} \times$ State \\
\hline \multicolumn{2}{|c|}{$\begin{array}{l}\text { We used the best-supported model from Model Suite I as the } \\
\text { base model in Model Suites II and III. } \\
{ }^{\ddagger} \text { Percent cover within a } 1 \text {-m radius of the nest. } \\
\text { We used each vegetation covariate in each iteration of these } \\
\text { models. }\end{array}$} \\
\hline
\end{tabular}


1. Spatial location. To account for potential variation in DSR across the Golden-winged Warbler's breeding range, we modeled state and population segment. Spatial variation in DSR occurred between populations in Ontario and Tennessee (Bulluck et al. 2013) and may be associated with location-specific variation in predator communities, weather patterns, or other variables not specifically accounted for in our models (Rotenberry and Wiens 1989). Each of our states encompassed 2-20 sites, so we recognized that state-scale estimates of DSR could obscure site-scale differences in DSR, e.g., wetland and upland sites in New York (Confer et al. 2010). However, our sites were similar within individual states or sample sizes were too small to account for variation among sites within states. We also aggregated states into two distinct and possibly disjunct segments of the Goldenwinged Warbler's breeding range (Roth et al. 2012): the Great Lakes (Minnesota and Wisconsin) and Appalachian Mountains population segments (North Carolina, New York, Pennsylvania, Tennessee, and West Virginia). The Great Lakes population segment has a larger population size (Roth et al. 2012), greater territory density (Streby et al. 2012, Frantz et al. 2015), and slower rates of population decline (Sauer et al. 2014) than the Appalachian Mountains population segment, which we hypothesized to be in part a consequence of greater DSR in the Great Lakes population segment.

2. Time. We assessed time using nest stage, time-within-season, and year covariates. Annual variation in DSR may be associated with biotic or abiotic variables such as fluctuations in predator abundance or weather (Rotenberry and Wiens 1989) that were not specifically accounted for by other model covariates. Passerine nest survival tends to decrease over time within a season (Grant et al. 2005, Bulluck et al. 2013), but in some cases may increase (Streby et al. 2014). Within-season trends in DSR may be curvilinear because of changing activity patterns of nest predators such as snakes, whose activity varies with reproductive and thermoregulatory stimuli (Sperry et al. 2008). Thus, we tested if DSR had a linear or quadratic relationship with time-within-season. We also tested for a relationship between DSR and nest stage (three categories: egg-laying, incubation, and brooding) because differences in auditory, olfactory, and visual cues at the nest site during different stages may affect predation rates (Skutch 1949).

3. Vegetation characteristics. We used percent cover of forb, grass, herbaceous (forb + grass), Rubus, woody, and shrub (Rubus + woody) within $1 \mathrm{~m}$ of the nest (hereafter referred to as forb, grass, herbaceous, Rubus, woody, or shrub cover), vegetation density within $10 \mathrm{~m}$ of the nest (hereafter referred to as vegetation density), distance to later successional forest edge (hereafter referred to as forest edge), and nest height as covariates in DSR models because these characteristics were associated with nest survival in previous studies (Confer et al. 2003, Bulluck and Buehler 2008, Roth et al. 2012, Bulluck et al. 2013, Aldinger and Wood 2014, Streby et al. 2014). We predicted that preferred levels of vegetation characteristics selected by individual warblers (approximately $5-45 \%$ forb, 5-45\% grass, $40-80 \%$ herbaceous, 5-40\% Rubus, $15-35 \%$ woody, and 5-50\% shrub cover and 10-30\% vegetation density; Roth et al. 2012, Terhune et al. 2015) would be associated with increased DSR. We also included site-level dominant vegetation type in our models in two categories: herbaceous-dominated, e.g., old field, or woodydominated, e.g., regenerating forest, nesting vegetation. We predicted that nests in herbaceous-dominated nesting vegetation would have lower DSR because of increased predation rates traditionally associated with field-forest edges (Gates and Gysel 1978).

To evaluate the relationship between DSR and the covariates outlined above, we used a two-staged model selection process (Fondell et al. 2008, Amundson and Arnold 2011, Thompson et al. 2012) with three model suites (Table 2) and Akaike's Information Criterion adjusted for small sample bias and overdispersion $\left(\mathrm{QAIC}_{c}\right)$ for model selection (Burnham and Anderson 2002). For Model Suite I (spatial-temporal covariates), we modeled DSR considering covariates representing dominant vegetation type, population segment, state, and year (categorical "dummy" variable) using all Golden-winged Warbler nests from all states and years. We then included the best-supported model from Model Suite I in each model evaluated in Model Suites II and III.

Model suite II incorporated intraseasonal covariates related to the progression of the nesting season (time-within-season) and nest stage (laying, incubation, and brooding) of Golden-winged Warblers. To account for latitudinal variation among states, we modeled state and time-within-season by constraining them as independent parameters (Dinsmore et al. 2002).

Model suite III assessed how DSR was associated with vegetation characteristics surrounding Golden-winged Warbler nests. We modeled vegetation characteristics as untransformed, continuous numerical covariates. For each vegetation covariate, we formulated three models with either linear, quadratic, or cubic terms. Curvilinear relationships may exist if DSR peaks at intermediate levels of the vegetation covariates, which may be preferred at Golden-winged Warbler nest sites, e.g., 40-80\% herbaceous cover (Terhune et al. 2015). We also formulated one model that included all of the vegetation cover covariates (forb, grass, Rubus, and woody cover). We formulated models with an interaction between each (linear) vegetation covariate and the covariate(s) in the best-supported model from Model Suite I to test if vegetation covariates were similarly associated with DSR across values of the spatial-temporal covariate. For Model Suite III, we removed Minnesota and North Carolina nests because these nests had incomplete vegetation data.

We evaluated competing models of DSR of Golden-winged Warbler nests using the nest survival model in program MARK (ver. 7.1, Colorado State University, Ft. Collins, Colorado, USA). We included nests that reached at least the egg-laying stage in analyses. We modeled the binomially distributed data with the user-defined, logit-link function while simultaneously considering associations with spatial-temporal, intraseasonal, and vegetation covariates. We used standard coding for analysis of data in MARK (Dinsmore et al. 2002, Rotella et al. 2004). For our analysis of nest stage, we assumed a 25-day nesting period, with 4 days for egg-laying, 11 days for incubation, and 10 days for brooding (Ehrlich et al. 1988, Confer et al. 2011). We did not standardize individual covariates, because the unstandardized 
Table 3. Model-selection results for daily survival rate of Golden-winged Warbler (Vermivora chrysoptera) nests from Model Suites I, II, and III in Minnesota, Wisconsin, New York, Pennsylvania, West Virginia, North Carolina, and Tennessee, 2008-2012. We used program MARK (ver. 7.1, Colorado State University, Ft. Collins, Colorado, USA) and Akaike's Information Criterion adjusted for small sample size and overdispersion (QAICc) for analysis of daily survival rate of nests. $K$ is the number of parameters in the model, QAICc is Akaike's Information Criterion adjusted for small sample size and overdispersion, $\triangle$ QAIC $_{c}$ is the difference in QAIC values $_{c}$ between individual models and the top model, and wi is the model weight. We only presented models where $w_{\mathrm{i}} \geq 0.01$. See Table 1 for the full list of models and their notation.

\begin{tabular}{|c|c|c|c|c|c|}
\hline Model Suite & Daily Survival Rate Model & $K$ & $\mathrm{QAIC}_{c}$ & $\Delta \mathrm{QAIC}_{c}$ & $w_{\mathrm{i}}$ \\
\hline \multirow{7}{*}{ I: Spatial-temporal } & State & 7 & 1240.48 & 0.00 & 0.73 \\
\hline & Constant & 1 & 1243.91 & 3.43 & 0.13 \\
\hline & VegType & 2 & 1245.70 & 5.22 & 0.05 \\
\hline & PopSeg & 2 & 1245.87 & 5.39 & 0.05 \\
\hline & Year & 5 & 1248.13 & 7.66 & 0.02 \\
\hline & Year x State & 25 & 1248.58 & 8.10 & 0.01 \\
\hline & Year + State & 11 & 1248.64 & 8.17 & 0.01 \\
\hline \multirow[t]{2}{*}{ II: Intraseasonal ${ }^{\dagger}$} & State $+\mathrm{T}$ & 8 & 1213.72 & 0.00 & 0.72 \\
\hline & State $+\mathrm{T}+\mathrm{TT}$ & 9 & 1215.56 & 1.85 & 0.28 \\
\hline \multirow[t]{26}{*}{ III: Vegetation ${ }^{\dagger+}$} & State $+\mathrm{GC}+\mathrm{GC}^{2}$ & 7 & 1167.32 & 0.00 & 0.15 \\
\hline & State & 5 & 1168.48 & 1.15 & 0.08 \\
\hline & State $+\mathrm{GC}+\mathrm{GC}^{2}+\mathrm{GC}^{3}$ & 8 & 1168.92 & 1.60 & 0.07 \\
\hline & State $+\mathrm{RC}+\mathrm{RC}^{2}$ & 7 & 1169.03 & 1.71 & 0.06 \\
\hline & State + Edge + Edge $^{2}$ & 7 & 1169.16 & 1.84 & 0.06 \\
\hline & State + GC & 6 & 1169.16 & 1.84 & 0.06 \\
\hline & State + Edge & 6 & 1169.28 & 1.96 & 0.06 \\
\hline & State + NestHt & 6 & 1169.34 & 2.02 & 0.05 \\
\hline & State + VegDen + VegDen ${ }^{2}$ & 7 & 1169.79 & 2.47 & 0.04 \\
\hline & State + FC & 6 & 1170.25 & 2.93 & 0.03 \\
\hline & State + WC & 6 & 1170.27 & 2.95 & 0.03 \\
\hline & State + Shrub & 6 & 1170.28 & 2.96 & 0.03 \\
\hline & State + VegDen & 6 & 1170.39 & 3.07 & 0.03 \\
\hline & State + Herb & 6 & 1170.47 & 3.14 & 0.03 \\
\hline & State + RC & 6 & 1170.47 & 3.15 & 0.03 \\
\hline & State $+\mathrm{RC}+\mathrm{RC}^{2}+\mathrm{RC}^{3}$ & 8 & 1170.93 & 3.60 & 0.02 \\
\hline & State + WC + WC & 7 & 1170.95 & 3.62 & 0.02 \\
\hline & State + Herb + Herb $^{2}$ & 7 & 1171.44 & 4.12 & 0.02 \\
\hline & State $+\mathrm{WC}+\mathrm{WC}^{2}+\mathrm{WC}^{3}$ & 8 & 1171.94 & 4.61 & 0.01 \\
\hline & State + GC + State $x$ GC & 10 & 1171.95 & 4.63 & 0.01 \\
\hline & State $+\mathrm{FC}+\mathrm{FC} 2$ & 7 & 1172.08 & 4.76 & 0.01 \\
\hline & State $+\mathrm{FC}+\mathrm{FC}^{2}+\mathrm{FC}^{3}$ & 8 & 1172.12 & 4.79 & 0.01 \\
\hline & State + Shrub + Shrub $^{2}$ & 7 & 1172.18 & 4.86 & 0.01 \\
\hline & State + Herb + Shrub & 7 & 1172.26 & 4.94 & 0.01 \\
\hline & State + Herb + Herb $^{2}+$ Herb $^{3}$ & 8 & 1173.17 & 5.85 & 0.01 \\
\hline & State + Shrub + Shrub $^{2}+$ Shrub $^{3}$ & 8 & 1173.74 & 6.42 & 0.01 \\
\hline
\end{tabular}

\footnotetext{
${ }^{\dagger}$ We used the best-supported model from Model Suite I as the base model in Model Suites II and III.

$\$$ For Model Suite III, we removed Minnesota $(n=18)$ and North Carolina $(n=8)$ nests because these nests had incomplete vegetation data.
}

covariates did not affect numerical optimization (Dinsmore et al. 2002, Rotella 2007). To maintain sample size and avoid potentially biased estimates associated with complete-case analysis (Knol et al. 2010, White and Carlin 2010), we used a multiple imputation approach to predict mean covariate values for missing vegetation data (Rubin 1976, Horton and Kleinman 2007), which comprised $2.7 \%$ of all values, and we incorporated uncertainty by resampling values from a mean normal distribution $( \pm 5 \%)$ based on the observed data. We excluded nests with no vegetation data from
Model Suite III, thus we were only predicting single values for individual nests.

We considered the model with the lowest QAIC value to be the best-supported model given the data and any models with $\triangle \mathrm{QAIC}_{c}$ $\leq 2$ were considered plausible (Burnham and Anderson 2002). We assessed the relative plausibility of each model in the model suite by comparing Akaike weights $\left(w_{i}\right)$. We did not present models with $w_{i}<0.01$ in our model selection results (Table 3 ). We modelaveraged parameter estimates and beta coefficients across all 
Table 4. Model-averaged (across models containing the covariate) coefficients for covariates in best-supported ( $\Delta$ QAICc $<2$ ) models of daily survival rate of Golden-winged Warbler (Vermivora chrysoptera) nests from Models Suites I, II, and III on sites located in Minnesota, Wisconsin, New York, Pennsylvania, West Virginia, North Carolina, and Tennessee, 2008-2012. See Table 1 for the full list of models and their notation.

\begin{tabular}{llccc}
\hline \hline Model Suite & Covariate & Estimate & SE & 95\% CI (Lower, Upper) \\
\hline I: Spatial-temporal & Minnesota ${ }^{\dagger}$ & 0.429 & 0.414 & $-0.383,1.240$ \\
& New York & 0.282 & 0.258 & $-0.223,0.788$ \\
& North Carolina ${ }^{\dagger}$ & 0.539 & 0.746 & $-0.923,2.001$ \\
& Pennsylvania & -0.274 & 0.205 & $-0.676,0.127$ \\
& Tennessee (intercept) & 4.173 & 0.322 & $3.542,4.804$ \\
& West Virginia & 0.120 & 0.216 & $-0.302,0.542$ \\
II: Intraseasonal & Wisconsin & 0.004 & 0.263 & $-0.511,0.520$ \\
& T & -0.043 & 0.034 & $-0.110,0.023$ \\
III: Vegetation ${ }^{\ddagger}$ & TT & 0.000 & 0.001 & $-0.001,0.001$ \\
& GC & 0.017 & 0.010 & $-0.004,0.037$ \\
& GC & 0.000 & 0.000 & $-0.001,0.000$ \\
& GC & 0.003 & 0.002 & $0.000,0.006$ \\
& RC & -0.018 & 0.012 & $-0.041,0.006$ \\
& RC & 0.000 & 0.000 & $0.000,0.001$ \\
& Edge $^{2}$ & -0.005 & 0.002 & $-0.009,-0.001$ \\
\hline
\end{tabular}

\footnotetext{
${ }^{\dagger}$ Interpret parameter estimates for Minnesota $(\mathrm{n}=18$ nests) and North Carolina ( $\mathrm{n}=8$ nests) with caution due to small sample sizes of nests.

${ }^{\star}$ For Model Suite III, we removed Minnesota and North Carolina nests because few of these nests had complete vegetation data.
}

models within each model suite and used beta coefficients to infer biological importance of covariates. We reported model-averaged beta coefficients $\left(B_{\text {Covariate }}\right)$, standard errors $(\mathrm{SE})$, and $95 \%$ confidence intervals $(\mathrm{CI})$ for covariates in plausible models.

\section{RESULTS}

We monitored 388 Golden-winged Warbler nests across all states and years (Fig. 1), resulting in 4642 exposure days and mean DSR of $0.960 \pm 0.003 \mathrm{SE}(95 \% \mathrm{CI}=0.955-0.965)$. Golden-winged Warbler nesting phenology varied by state (Fig. 2). Overall, we discovered the earliest egg on 1 May 2010 in Tennessee and observed the latest active nest on 20 July 2008 in Wisconsin. We obtained additional nesting phenology information for Minnesota (2011-2012, H. M. Streby, unpublished data) and North Carolina (2012, C. G. Smalling, unpublished data); these nests were not included in our other analyses because they were not sampled using our standardized protocols.

\section{Daily survival rate of Golden-winged Warbler nests}

Among spatial-temporal models of DSR in Model Suite I, the model containing state was best-supported $\left(\mathrm{QAIC}_{c}\right.$ weight $\left[w_{i}\right]=$ 0.73, Table 3). DSR was least in Pennsylvania and greatest in Minnesota and New York, although 95\% CIs of beta coefficients overlapped among states (Table 4). No other model in Model Suite I had substantial support $\left(\Delta \mathrm{QAIC}_{c} \leq 2\right.$, Table 3$)$.

Among intraseasonal models of DSR in Model Suite II, the bestsupported and most plausible $\left(w_{i}=0.72\right)$ model included state and a linear time-within-season covariate (Table 3 ). A second model including state and a quadratic time covariate had substantial support $\left(\triangle\right.$ QAIC $\left._{c}=1.85\right)$ but was less plausible $\left(w_{i}=\right.$ 0.28 , Table 3 ). However, the beta coefficient $95 \%$ CIs overlapped zero for the linear and quadratic relationships between timewithin-season and DSR (Table 4), suggesting low biological importance of time-within-season on DSR.

Fig. 2. Mean ( $\pm \mathrm{SE}$ ) annual Golden-winged Warbler (Vermivora chrysoptera) first egg dates (left end of bar) and last nest active dates (right end of bar). The timing of the nesting season was delayed as state latitude increased. Where available, we obtained data to fill gaps among years for Minnesota (2011-2012, H. M. Streby, unpublished data) and North Carolina (2012, C. G. Smalling, unpublished data); these nests were not included in our other analyses because they were not sampled using our standardized protocols.

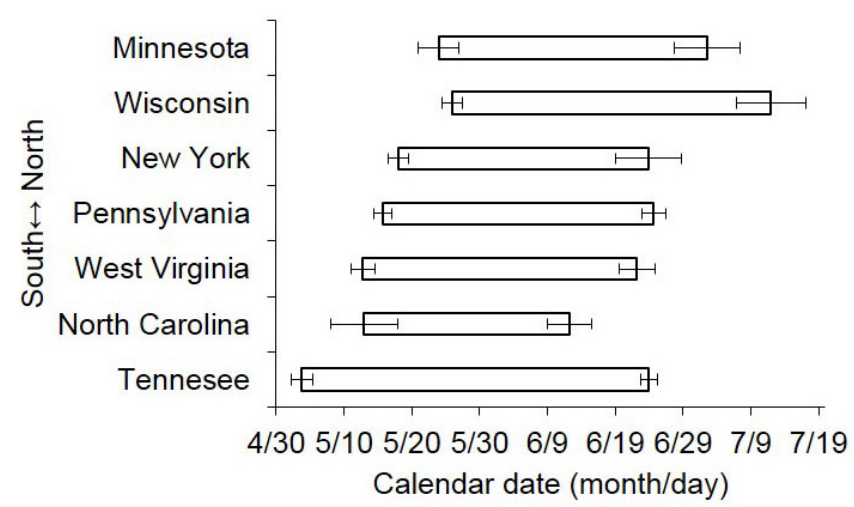


Among vegetation models of DSR in Model Suite III, the bestsupported model included state and linear and quadratic terms for percent grass cover (Table 3). This model predicted that DSR was relatively constant until percent grass cover reached $50 \%$, at which point DSR declined (Fig. 3A). Based on model weights, this best-supported model $\left(w_{i}=0.15\right)$ was 1.7 times more plausible than the next best-supported model that included only state $\left(\Delta \mathrm{QAIC}_{c}=1.15, w_{i}=0.09\right)$. Models containing state and percent Rubus cover (Fig. 3B) and models containing state and distance to forest edge (Fig. 3C) also had substantial support ( $\triangle$ QAIC $_{c} \leq$ 2 , Table 3). Outlying values likely contributed to apparently weak associations (i.e., some beta coefficient 95\% CIs that overlapped zero, Table 4) between vegetation covariates and DSR in our top models (Fig. 3). We also ran models with interactions between state and vegetation covariates (e.g., DSR State + GC + State $x$ GC) to evaluate if vegetation covariates were associated with DSR similarly among states. Grass and Rubus cover and distance to forest edge had similar associations with DSR among states since our models with interactions had considerably less support $\left(\Delta\right.$ QAIC $\left._{c}>4\right)$ than our top model (Table 3$)$.

\section{DISCUSSION}

We examined whether there was a common set of vegetation characteristics linked to DSR across broad, in terms of geography and vegetation community type, portions of the Golden-winged Warbler breeding range. This question is important because it provides a foundation for being able to successfully manage vegetation communities to increase DSR through regional conservation prescriptions. If these vegetation-DSR relationships are not generalizable across broad scales, then management prescriptions to improve DSR must be developed at a more local scale or by vegetation community type. Of several different nestsite characteristics related to vegetation structure and composition, only three covariates were included in the DSR models with substantial support: grass and Rubus cover and distance to forest edge. Although our sample of nests was dominated spatially and proportionally by the Appalachian Mountains population segment ( $85 \%$ of nests), all vegetation communities commonly used by Golden-winged Warblers for nesting (summarized in Confer et al. 2011) were represented in our collective sample.

Among the models in Model Suite I, the DSR model containing only state had the most support. Our states spanned $1140 \mathrm{~km}$ in latitude, $1770 \mathrm{~km}$ in longitude, and $1290 \mathrm{~m}$ in elevation and included differences in landscape context, disturbance regime, and vegetation community composition, which in turn may have resulted in different predator communities, predation patterns, and vulnerability of nests. Spatial location (Bulluck et al. 2013), landscape context (Peterson et al. 2015), disturbance regimes (Kubel and Yahner 2008, Roth et al. 2014), and vegetation community composition (Confer et al. 2010) have all been linked to variation in Golden-winged Warbler reproductive performance. Thus, approximately at the scale of our states may lie an ultimate, as opposed to proximate, i.e., state, correlate that could provide a more mechanistic understanding of DSR of Golden-winged Warbler nests. Although DSR was statistically similar among states, discovery of the variable(s) underlying our state covariate may lead to clearer statistical and biological conclusions about spatial variation in DSR and improved regional conservation strategies.
Fig. 3. Relationships ( $\pm 95 \%$ CI, dashed lines) between (A) grass and (B) Rubus cover within $1 \mathrm{~m}$ and $(\mathrm{C})$ distance to a later successional forest edge and daily survival rate (DSR) of Golden-winged Warbler (Vermivora chrysoptera) nests, based on models with substantial support from Model Suite III (A = DSR [State + grass cover + grass cover2], B = DSR [State + Rubus cover + Rubus cover2], C = DSR [State + edge distance + edge distance2]). DSR remained relatively constant until grass cover reached 50\%, after which DSR declined (A). DSR was lowest at about 30\% Rubus cover (B). DSR had a negative association with distance to a later successional forest edge (C). Almost all (95\%) of the nests had $<64 \%$ grass cover and $<60 \%$ Rubus cover within $1 \mathrm{~m}$ and were $<152 \mathrm{~m}$ from a later successional forest edge (vertical lines).
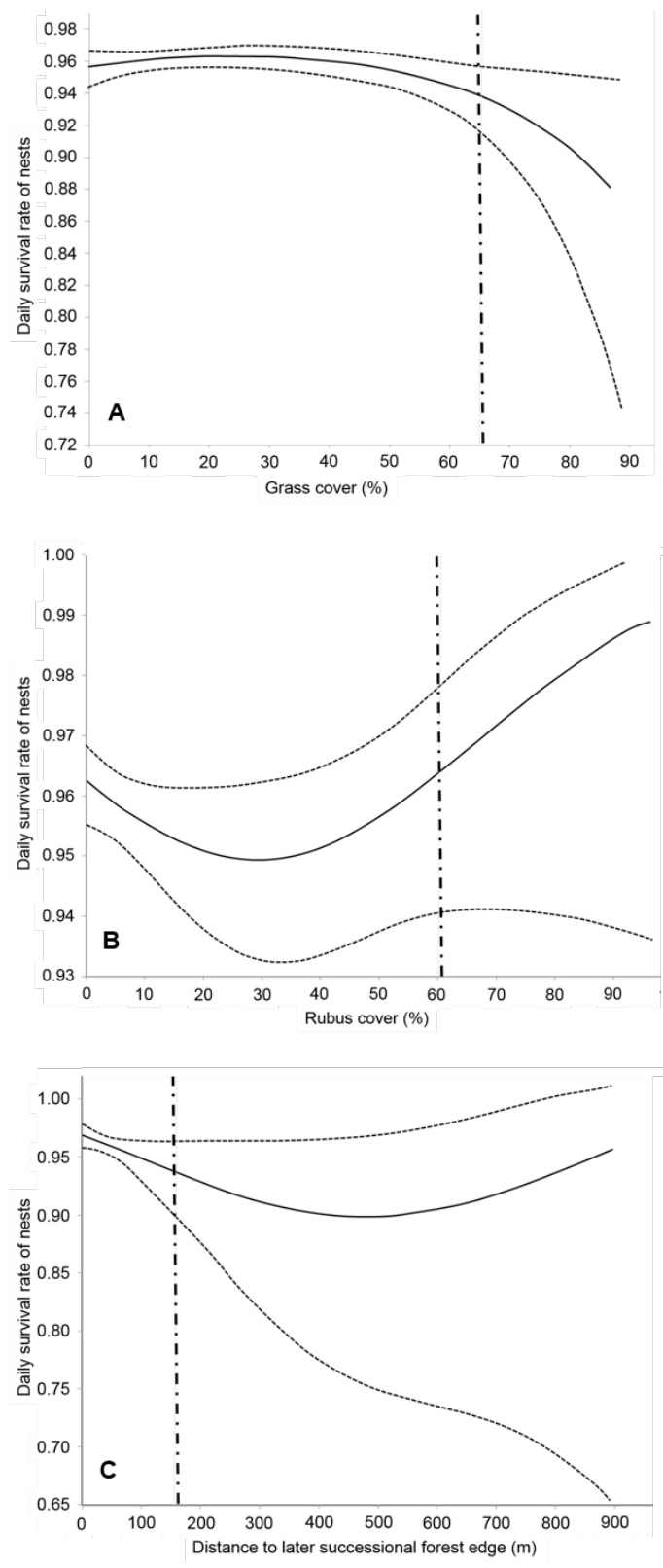
Of the vegetation covariates in our DSR models, percent grass cover may have the most potential for management. Furthermore, because our model with a state by grass cover interaction had little support, grass cover management targets appear to be similar across the Golden-winged Warbler's breeding range. Grass cover is an important characteristic of Golden-winged Warbler nesting vegetation (Confer et al. 2003, Buehler et al. 2007, Confer et al. 2011, Terhune et al. 2015). Compared to random locations in their territories, Golden-winged Warblers preferred nest sites with $5-50 \%$ grass cover within $1 \mathrm{~m}$ (Terhune et al. 2015). As we predicted, DSR was consistently high within this range and declined when grass cover exceeded $50 \%$. Nests in vegetation with $>50 \%$ grass cover may be less concealed (total-foliage hypothesis, Martin 1993), more easily located by predators (potential-prey hypothesis, Martin 1993), or exposed to a different predator community (Thompson 2007), resulting in increased predation rates. In addition, Terhune et al. (2015) suggested that selection of certain habitat components was linked to vegetation community type, i.e., herbaceous- versus woody-dominated, combined with varying site-level vegetation conditions whereby vegetation community type may drive local, nest site selection. Thus, the grass cover associated with DSR may not always be taxon-specific and therefore may differ among contexts, e.g., upland versus wetland sites, as to which taxon is needed to provide the necessary nesting structure. For example, Poaceae grasses and Cyperaceae sedges provided nesting substrate for upland (relatively low nest survival) and wetland (relatively high nest survival) populations, respectively, among our New York sites (Confer et al. 2010). Whereas we did not have adequate data to evaluate differences among grass taxa or wetlands and uplands, we infer that sedges and rushes among wetland sites may serve as structural equivalents to grass cover in upland sites. We add that certain taxa, e.g., invasive Phragmites displace sedges, may not support nesting Golden-winged Warblers (Confer et al. 2010, 2011). More research will elucidate these relationships and refine management guidelines, particularly among wetland sites.

The other two vegetation covariates associated with DSR, Rubus cover and distance to forest edge, also are important features of Golden-winged Warbler nest sites (e.g., Buehler et al. 2007, Confer et al. 2011, Aldinger and Wood 2014). Similar to grass cover, models with a state by Rubus cover or state by distance to forest edge interaction had little support, so management targets may be similar across the Golden-winged Warbler's breeding range. Although Rubus cover and distance to forest edge showed somewhat uncertain relationships with DSR, the DSR curves for these two covariates (Fig. 3) revealed this was because of outlying values, particularly for distance to forest edge (Fig. 3C). At values less than the 95th percentile (152 $\mathrm{m}$ in Fig. 3C), we observed a clear negative trend in DSR with distance to forest edge, suggesting an edge effect associated with the interface between shrublands or young forests and near $100 \%$ closed-canopy forests. Nest predation along edges may not be as detrimental for shrubland birds (Woodward et al. 2001) as it is for forest-interior birds (Batáry and Báldi 2004). In our study, nest sites farther from a forest edge in large openings might have more grass cover (e.g., managed old field sites in Pennsylvania, grazed livestock pastures with soft edges in West Virginia, or regenerating aspen stands where shading from the forest edge reduced grass cover along edges in Wisconsin), resulting in greater predation rates. In contrast, DSR in Minnesota increased away from edges of later successional forests (Streby et al. 2014). Our definition of forest edge appears to have differed from that of Streby et al. (2014), perhaps leading to contradictory results. The forests to which we measured had near $100 \%$ canopy-closure, generally preventing the growth of the herbaceous vegetation and shrubs needed for nesting cover. Streby et al. (2014) used canopy height rather than canopy closure to define forest and their forested areas had dense undergrowth.

The primary objective of our study was to determine if a common set of vegetation characteristics among the different vegetation communities commonly used for nesting across the Goldenwinged Warbler's breeding range was associated with DSR. Among the covariates we modeled, grass (negative association with DSR above $50 \%$ grass cover) and Rubus (DSR lowest at $\sim 30 \%$ Rubus cover) cover within 1-m of the nest and distance from the nest to a later successional forest edge (negative association with DSR) may be relevant management targets for altering Goldenwinged Warbler DSR among our states, particularly in the Appalachian Mountains population segment. We recognize, however, that variation in DSR among our states may be attributable to additional characteristics that we did not measure. As such, it is important to consider our results along with contextspecific studies (e.g., Confer et al. 2010, Bulluck et al. 2013, Aldinger and Wood 2014) and management plans (e.g., Bakermans et al. 2011; Golden-winged Warbler Working Group $2013 a, 2013 b$ ) during conservation planning. For example, a key consideration for land managers around our Minnesota and New York sites would be reproductive performance in wetland versus upland settings (Confer et al. 2010, Peterson et al. 2015, Streby et al. 2015). A universal consideration for land managers is the potential for contact with Blue-winged Warblers, which may replace Golden-winged Warblers regardless of the quality of nesting vegetation for Golden-winged Warblers (Gill 1980, 2004, Confer et al. 2003). Future studies that evaluate DSR in vegetation communities where managers implemented our management guidelines will provide opportunities to improve upon our guidelines.

Responses to this article can be read online at: http://www.ace-eco.org/issues/responses.php/748

\section{Acknowledgments:}

We thank the many supporters of this research, including Audubon North Carolina, Bald Eagle State Park - Pennsylvania, Blue Ridge Conservancy, Cornell Lab of Ornithology, C. Paynter, D. Paynter, EcoQuest Travel, Garden Club of America, Grace Jones Richardson Trust, Habitat Forever, Indiana University of Pennsylvania, J. Roushdy, Michigan Technological University, National Fish and Wildlife Foundation, National Science Foundation, North Carolina State Parks, North Carolina Wildlife Resources Commission, Oneida County Forests, Pennsylvania Bureau of Forestry, Pennsylvania Department of Conservation and Natural Resources, Potlatch Corporation, Ruffed Grouse Society, Southern Appalachian Highlands Conservancy, Tennessee Wildlife Resources Agency, Tennessee Ornithological Society, The Nature 
Conservancy, Tomahawk Timberlands, University of Minnesota, University of Tennessee, U.S. Forest Service Monongahela National Forest, U.S. Forest Service Northern Research Station, U.S. Geological Survey Cooperative Research Units Program, U. S. Natural Resource Conservation Service, West Virginia Division of Natural Resources, Wisconsin Focus on Energy, Wisconsin Department of Natural Resources, and Wisconsin Society of Ornithology. We also thank the field assistants that worked tirelessly to find and monitor nests and measure associated vegetation. D. E. Andersen, M.E. McDermott, S. M. Peterson, and H. M. Streby provided extensive input and review on earlier drafts of this manuscript. We completed this study under the auspices of the following IACUC protocols: 03-0708 (Indiana University of Pennsylvania), SO2-4 (Ithaca College), L0111 and L0200 (Michigan Technological University), 0710A19381 (University of Minnesota), 561-1101 (University of Tennessee), and 07-0303 and 10-0201 (West Virginia University). Use of trade names does not imply endorsement by the U.S. Federal Government.

\section{LITERATURE CITED}

Aldinger, K. R., and P. B. Wood. 2014. Reproductive success and habitat characteristics of Golden-winged Warblers in highelevation pasturelands. Wilson Journal of Ornithology 126:279-287. http://dx.doi.org/10.1676/13-114.1

Amundson, C. L., and T. W. Arnold. 2011. The role of predator removal, density-dependence, and environmental factors on Mallard duckling survival in North Dakota. Journal of Wildlife Management 75:1330-1339. http://dx.doi.org/10.1002/jwmg.166

Bakermans, M. H., J. L. Larkin, B. W. Smith, T. M. Fearer, and B. C. Jones. 2011. Golden-winged Warbler habitat best management practices for forestlands in Maryland and Pennsylvania. American Bird Conservancy, The Plains, Virginia, USA.

Batáry, P., and A. Báldi. 2004. Evidence of an edge effect on avian nest success. Conservation Biology 18:389-400. http://dx.doi. org/10.1111/j.1523-1739.2004.00184.X

Buehler, D. A., A. M. Roth, R. Vallender, T. C. Will, J. L. Confer, R. A. Canterbury, S. B. Swarthout, K. V. Rosenberg, and L. P. Bulluck. 2007. Status and conservation priorities of Goldenwinged Warbler (Vermivora chrysoptera) in North America. Auk 124:1439-1445. http://dx.doi.org/10.1642/0004-8038(2007)124[1439: SACPOG]2.0.CO;2

Bulluck, L. P., and D. A. Buehler. 2008. Factors influencing Golden-winged Warbler (Vermivora chrysoptera) nest-site selection and nest survival in the Cumberland Mountains of Tennessee. Auk 125:551-559. http://dx.doi.org/10.1525/auk.2008.07075

Bulluck, L. P., D. A. Buehler, R. Vallender, and R. J. Robertson. 2013. Demographic comparison of Golden-winged Warbler (Vermivora chrysoptera) populations in northern and southern extremes of their breeding range. Wilson Journal of Ornithology 125:479-490. http://dx.doi.org/10.1676/12-154.1

Burnham, K. P., and D. R. Anderson. 2002. Model selection and multimodel inference: a practical information-theoretic approach. Second edition. Springer-Verlag, New York, New York, USA. http://dx.doi.org/10.1007/b97636

Ciuzio, E., W. L. Hohman, B. Martin, M. D. Smith, S. Stephens, A. M. Strong, and T. Vercauteren. 2013. Opportunities and challenges to implementing bird conservation on private lands. Wildlife Society Bulletin 37:267-277. http://dx.doi.org/10.1002/ wsb. 266

Confer, J. L., K. W. Barnes, and E. C. Alvey. 2010. Golden- and Blue-winged Warblers: distribution, nesting success, and genetic differences in two habitats. Wilson Journal of Ornithology 122:273-278. http://dx.doi.org/10.1676/09-136.1

Confer, J. L., P. Hartman, and A. Roth. 2011. Golden-winged Warbler (Vermivora chrysoptera). In A. Poole, editor. Birds of North America. Number 20. Cornell Laboratory of Ornithology, Ithaca, New York, USA. [online] URL: http://bna.birds.cornell. edu/bna/species/020/articles/introduction http://dx.doi.org/10.2173/ bna. 20

Confer, J. L., J. L. Larkin, and P. E. Allen. 2003. Effects of vegetation, interspecific competition, and brood parasitism on Golden-winged Warbler (Vermivora chrysoptera) nesting success. Auk 120:138-144. http://dx.doi.org/10.1642/0004-8038(2003)120 [0138:EOVICA]2.0.CO;2

Dinsmore, S. J., G. C. White, and F. L. Knopf. 2002. Advanced techniques for modeling avian nest survival. Ecology 83:3476-3488. http://dx.doi.org/10.1890/0012-9658(2002)083[3476: ATFMAN]2.0.CO;2

Dyer, J. M. 2006. Revisiting the deciduous forests of eastern North America. Bioscience 56:341-352. http://dx.doi.org/10.1641/0006-3568 (2006)56[341:RTDFOE]2.0.CO;2

Ehrlich, P. R., D. S. Dobkin, and D. Wheye. 1988. The birder's handbook: a field guide to the natural history of North American birds. Simon and Schuster, New York, New York, USA.

Ficken, M. S., and R. W. Ficken. 1968. Courtship of Blue-winged Warblers, Golden-winged Warblers, and their hybrids. Wilson Bulletin 80:161-172

Fondell, T. F., D. A. Miller, J. B. Grand, and R. M. Anthony. 2008. Survival of Dusky Canada Goose goslings in relation to weather and annual nest success. Journal of Wildlife Management 71:1614-1621.

Frantz, M. W., K. R. Aldinger, P. B. Wood, J. Duchamp, T. Nuttle, A. Vitz, and J. L. Larkin. 2015. Space and habitat use of breeding Golden-winged Warblers in the central Appalachian Mountains. Studies in Avian Biology, in press.

Gates, J. E., and L. W. Gysel. 1978. Avian nest dispersion and fledging success in field-forest ecotones. Ecology 59:871-883. http://dx.doi.org/10.2307/1938540

Gill, F. B. 1980. Historical aspects of hybridization between Bluewinged and Golden-winged warblers. Auk 97:1-18.

Gill, F. B. 2004. Blue-winged Warblers (Vermivora pinus) versus Golden-winged Warblers (V. chrysoptera). Auk 121:1014-1018. http://dx.doi.org/10.1642/0004-8038(2004)121[1014:BWVPVG]2.0. $\mathrm{CO} ; 2$

Golden-winged Warbler Working Group. 2013a. Best management practices for Golden-winged Warbler habitats in the Appalachian region. [online] URL: http://www.gwwa.org/plan

Golden-winged Warbler Working Group. 2013b. Best management practices for Golden-winged Warbler habitats in the Great Lakes region. [online] URL: http://www.gwwa.org/plan 
Grant, T. A., T. L. Shaffer, E. M. Madden, and P. J. Pietz. 2005. Time-specific variation in passerine nest survival: new insights into old questions. Auk 122:661-672. http://dx.doi.org/10.1642/0004-8038 (2005)122[0661:TVIPNS]2.0.CO;2

Helm, D. J., and B. R. Mead. 2004. Reproducibility of vegetation cover estimates in south-central Alaska forests. Journal of Vegetation Science 15:33-40. http://dx.doi.org/10.1111/j.1654-1103.2004. tb02234.x

Horton, N. J., and K. P. Kleinman. 2007. Much ado about nothing: a comparison of missing data methods and software to fit incomplete data regression models. American Statistician 61:79-90. http://dx.doi.org/10.1198/000313007X172556

Hunter, W. C., D. A. Buehler, R. A. Canterbury, J. L. Confer, and P. B. Hamel. 2001. Conservation of disturbance-dependent birds in eastern North America. Wildlife Society Bulletin 29:440-455.

Kercher, S. M., C. B. Frieswyk, and J. B. Zedler. 2003. Effects of sampling teams and estimation methods on the assessment of plant cover. Journal of Vegetation Science 14:899-906. http://dx. doi.org/10.1111/j.1654-1103.2003.tb02223.x

Knol, M. J., K. J. M. Janssen, A. R. T. Donders, A. C. G. Egberts, E. R. Heerdink, D. E. Grobbee, K. G. M. Moons, and M. I. Geerlings. 2010. Unpredictable bias when using the missing indicator method or complete case analysis for missing confounder values: an empirical example. Journal of Clinical Epidemiology 63:728-736. http://dx.doi.org/10.1016/j.jclinepi.2009.08.028

Kubel, J. E., and R. H. Yahner. 2008. Quality of anthropogenic habitat for Golden-winged Warblers in Central Pennsylvania. Wilson Journal of Ornithology 120:801-812. http://dx.doi. org/10.1676/06-114.1

Luscier, J. D., W. L. Thompson, J. M. Wilson, B. E. Gorham, and L. D. Dragut. 2006. Using digital photographs and object-based image analysis to estimate percent ground cover in vegetation plots. Frontiers in Ecology and the Environment 4:408-413. http:// dx.doi.org/10.1890/1540-9295(2006)4[408:UDPAOI]2.0.CO;2

Martin, T. E. 1993. Nest predation and nest sites. Bioscience 43:523-532. http://dx.doi.org/10.2307/1311947

Martin, T. E., and G. R. Geupel. 1993. Nest-monitoring plots: methods for locating nests and monitoring success. Journal of Field Ornithology 64:507-519.

Nudds, T. D. 1977. Quantifying the vegetative structure of wildlife cover. Wildlife Society Bulletin 5:113-117.

Percy, K. L. 2012. Effects of prescribed fire and habitat on Goldenwinged Warbler (Vermivora chrysoptera) abundance and nest survival in the Cumberland Mountains of Tennessee. Thesis. University of Tennessee, Knoxville, Tennessee, USA.

Peterson, S. M., H. M. Streby, and D. E. Andersen. 2015. Impact of landscape composition on Golden-winged Warbler full-season productivity. Studies in Avian Biology, in press.

Rotella, J. J. 2007. Nest survival models. Chapter 17 in E. Cooch and G. White, editors. Program MARK: a gentle introduction. Thirteenth edition. [online] URL: http://www.phidot.org/ software/mark/docs/book
Rotella, J. J., S. J. Dinsmore, and T. L. Shaffer. 2004. Modeling nest-survival data: a comparison of recently developed methods that can be implemented in MARK and SAS. Animal Biodiversity and Conservation 27:187-205.

Rotenberry, J. T., and J. A. Wiens. 1989. Reproductive biology of shrubsteppe passerine birds: geographical and temporal variation in clutch size, brood size, and fledging success. Condor 91:1-14. http://dx.doi.org/10.2307/1368142

Roth, A. M., D. J. Flaspohler, and C. R. Webster. 2014. Legacy trees in young aspen forest improves nesting habitat quality for Golden-winged Warbler (Vermivora chrysoptera). Forest Ecology and Management 321:61-70. http://dx.doi.org/10.1016/j. foreco.2013.07.047

Roth, A. M., R. W. Rohrbaugh, T. Will, and D. A. Buehler, editors. 2012. Golden-winged Warbler status review and conservation plan. [online] URL: http://www.gwwa.org/plan

Rubin, D. B. 1976. Inference and missing data. Biometrika 63:581-592. http://dx.doi.org/10.1093/biomet/63.3.581

Sauer, J. R., J. E. Hines, J. E. Fallon, K. L. Pardieck, D. J. Ziolkowski, Jr., and W. A. Link. 2014. The North American breeding bird survey, results and analysis 1966 - 2012. Version 02.19.2014 USGS Patuxent Wildlife Research Center, Laurel, Maryland, USA.

Skutch, A. F. 1949. Do tropical birds rear as many young as they can nourish? Ibis 91:430-455. http://dx.doi.org/10.1111/ j.1474-919X.1949.tb02293.x

Söderström, B., T. Pärt, and J. Rydén. 1998. Different nest predator faunas and nest predation risk on ground and shrub nests at forest ecotones: an experiment and a review. Oecologia 117:108-118. http://dx.doi.org/10.1007/s004420050638

Sperry, J. H., R. G. Peak, D. A. Cimprich, and P. J. Weatherhead. 2008. Snake activity affects seasonal variation in nest predation risk for birds. Journal of Avian Biology 39:379-383. http://dx.doi. org/10.1111/j.0908-8857.2008.04451.x

Streby, H. M., and D. E. Andersen. 2013. Testing common assumptions in studies of songbird nest success. Ibis 155:327-337. http://dx.doi.org/10.1111/ibi.12018

Streby, H. M., J. P. Loegering, and D. E. Andersen. 2012. Spotmapping underestimates song-territory size and use of mature forest by breeding Golden-winged Warblers in Minnesota, USA. Wildlife Society Bulletin 36:40-46. http://dx.doi.org/10.1002/ wsb. 118

Streby, H. M., S. M. Peterson, and D. E. Andersen. 2015. Survival and habitat use of fledgling Golden-winged Warblers in the western Great Lakes region. Studies in Avian Biology, in press.

Streby, H. M., J. M. Refsnider, S. M. Peterson, and D. E. Andersen. 2014. Retirement investment theory explains patterns in songbird nest-site choice. Proceedings of the Royal Society of London B 281:20131834. http://dx.doi.org/10.1098/rspb.2013.1834

Symstad, A. J., C. L. Wienk, and A. D. Thorstenson. 2008. Precision, repeatability, and efficiency of two canopy-cover estimate methods in northern Great Plains vegetation. Rangeland Ecology and Management 61:419-429. http://dx.doi.org/10.2111/08-010.1 
Terhune, T. M., II, K. R. Aldinger, D. A. Buehler, J. L. Confer, D. J. Flaspohler, J. L. Larkin, J. P. Loegering, K. L. Percy, A. M. Roth, C. Smalling, and P. B. Wood. 2015. Golden-winged Warbler nest-site habitat selection. Studies in Avian Biology, in press.

Thompson, F. R., III. 2007. Factors affecting nest predation on forest songbirds in North America. Ibis 149:98-109. http://dx.doi. org/10.1111/j.1474-919X.2007.00697.x

Thompson, F. R., III, and D. E. Burhans. 2003. Predation of songbird nests differs by predator and between field and forest habitats. Journal of Wildlife Management 67:408-416. http://dx. doi.org/10.2307/3802781

Thompson, F. R., III, T. M. Donovan, R. M. DeGraaf, J. Faaborg, and S. K. Robinson. 2002. A multi-scale perspective of the effects of forest fragmentation on birds in eastern forests. Studies in Avian Biology 24:8-19.

Thompson, S. J., T. W. Arnold, and S. Vacek. 2012. Impact of encroaching woody vegetation on nest success of upland nesting waterfowl. Journal of Wildlife Management 76:1635-1642. http:// dx.doi.org/10.1002/jwmg.415

Weatherhead, P. J., and G. Blouin-Demers. 2004. Understanding avian nest predation: why ornithologists should study snakes. Journal of Avian Biology 35:185-190. http://dx.doi.org/10.1111/ j.0908-8857.2004.03336.x

White, I. R., and J. B. Carlin. 2010. Bias and efficiency of multiple imputation compared with complete-case analysis for missing covariate values. Statistics in Medicine 29:2920-2930. http://dx. doi.org/10.1002/sim.3944

Woodward, A. A., A. D. Fink, and F. R. Thompson III. 2001. Edge effects and ecological traps: effects on shrubland birds in Missouri. Journal of Wildlife Management 65:668-675. http://dx. doi.org/10.2307/3803018 